\title{
Glycosphingolipids of rabbit endometrium and their changes during pregnancy
}

\author{
Z. Zhu ${ }^{1}$, L. Cheng ${ }^{1}$, Z. Tsui ${ }^{1}$, S. Hakomori ${ }^{2}$ and B. A. Fenderson ${ }^{3 *}$ \\ 'Department of Biochemistry, Dalian Medical College, Dalian 116023, People's Republic of China; \\ 'The Biomembrane Institute and University of Washington, 201 Elliott Ave West, Seattle, \\ WA 98119, USA; and ${ }^{3}$ Department of Pathology and Cell Biology, Jefferson Medical College, \\ 1020 Locust Street, Philadelphia, PA 19107, USA
}

\begin{abstract}
Summary. The glycolipids of nonpregnant and pregnant rabbit endometrium were characterized using a combination of biochemical and immunochemical techniques. Quantitative analyses indicated a 70\% decline in acidic glycolipid (ganglioside) content during early pregnancy (day 6), and a $2 \cdot 5$-fold increase in neutral glycolipid content during later pregnancy (day 26). The major gangliosides of rabbit endometrium were identified by thin-layer chromatography as GM3 and GD3, with minor amounts of GMI, GDla and GT1b. The major neutral glycolipids were identified similarly as globo-series structures Gb3 and Gb4. Monoclonal antibodies (mAbs) directed to glycolipid antigens permitted the detection of additional glycolipid species, including sialylated, sulfated and fucosylated lacto-series structures. Difucosyl Le ${ }^{y}$ structure (defined by mAb AH-6) and sulfated-galactosyl structure (defined by mAb VESP 6.2) were identified by indirect immunofluorescence along the luminal surface of the endometrium during the implantation period. Rapid changes in the glycolipid composition of endometrial cells during early pregnancy may facilitate embryo adhesion and trophectoderm outgrowth during implantation.
\end{abstract}

Ke'words: endometrium; glycolipids; pregnancy; immunohistochemistry; rabbit

\section{Introduction}

The carbohydrate chains of cell surface glycolipids, glycoproteins and proteoglycans may play a crucial role in regulating maternal-fetal interactions during implantation and early development. For example, uterine receptivity to blastocyst attachment is known to be associated with changes in (i) the glycoprotein composition of the epithelium (Ricketts et al., 1984; Anderson et al., 1986), (ii) the surface charge of the apical glycocalyx (Hewitt et al., 1979; Murphy \& Rogers, 1981; Anderson \& Hoffman, 1984) and (iii) the profile of glycoproteins secreted into the luminal fluid (Bell et al., 1986). The preimplantation embryo also undergoes a complex programme of glycosylation changes (reviewed by Fenderson et al., 1990). Together, these changes in surface carbohydrate may regulate contacts between the cell surface membranes of trophectoderm and endometrium. Indeed, blood group $\mathrm{H}$ antigen, which is highly expressed on the luminal surface of mouse endometrium (Kimber et al., 1988; Kimber \& Lindenberg, 1990), has been implicated as a ligand for trophectoderm adhesion (Lindenberg et al., 1988). In addition, lactosaminoglycans have been identified as receptors for endometrial cell adhesion (Dutt et al., 1987) and trophectodermal cell migration (Hathaway et al., 1989).

Glycolipids are ubiquitous components of the plasma membrane. They consist of ceramide embedded in the outer leaflet of the lipid bilayer and oligosaccharide chains extending into

${ }^{*}$ Correspondence and reprint requests. 
the aqueous environment at the cell surface (reviewed by Thompson \& Tillack, 1985). There is considerable variation in the oligosaccharide sequence and ceramide composition of membrane glycolipids: over 300 neutral and acidic glycolipid species have been described (Hannum \& Bell, 1989). This structural diversity may contribute to the specialization and function of the plasma membrane. For example, glycolipids are hypothesized to enhance the stability of the lipid bilayer (Pascher, 1976), regulate transmembrane signalling (Hanai et al., 1988; Nojiri et al., 1991), and mediate cell interaction through carbohydrate-protein (Springer \& Lasky, 1991) and carbohydrate-carbohydrate (Eggens et al., 1989; Kojima \& Hakomori, 1989) interactions.

We described changes in the glycolipid composition of human myometrium and endometrium during the menstrual cycle, pregnancy and ageing (Zhu et al., 1990). The results indicated an overall decline in polysialoganglioside during early pregnancy, with a corresponding increase in neutral glycolipid. We suggested that the appearance of novel glycolipids in the uterus could provide receptors for various hormones, and that the overall increase in neutral glycolipid during pregnancy was important for maternal-fetal interactions. In this report, we extend our analyses to a second species, the rabbit, and use immunohistochemical procedures to localize specific glycolipid antigens within the uterus.

\section{Materials and Methods}

\section{Tissues}

Uteri were removed from New Zealand White rabbits at specific reproductive stages: nonpregnant (oestrus), early pregnancy (day 6), mid-pregnancy (day 18) and late pregnancy (day 26). The day of mating was considered day 0 of pregnancy. For glycolipid analyses, endometrium was isolated by scraping the uterine lumen. Implantation sites were excluded from analysis, but no attempt was made to distinquish mesometrium from anti-mesometrium. Samples were collected from three rabbits at each reproductive stage. For immunohistochemical analyses, segments of uteri were transferred to embedding compound (Miles Laboratories, Naperville, IL, USA) and frozen immediately on dry ice.

\section{Glycolipid extraction and characterization}

Glycolipids were extracted from 1-2 g of rabbit endometrium according to the method of Chien et al. (1978). In brief, an acetone powder of each sample was extracted sequentially using chloroform:methanol (CM) 2:1, CM 1:1 and CM 1:2. Neutral and acidic glycolipids were separated by ion-exchange chromatography using DEAE-Sephadex A25 (Pharmacia, Uppsala, Sweden), as described previously (Ledeen \& Yu, 1982). Gangliosides were purified further by alkaline hydrolysis, dialysed against water, and lyophilized. Neutral glycolipids were separated from phospholipids and cholesterol by chromatography (Vance \& Sweeley, 1967) using Bio-Sil silica gel columns (Bio-Rad, Richmond, CA, USA). Total lipid-bound sialic acid was determined by the method of Aminoff (1961): in brief, glycolipid samples were oxidized with periodic acid, reduced with sodium arsenate, reacted with thiobarbituric acid at $100^{\circ} \mathrm{C}$ and monitored for colour reaction at $549 \mathrm{~nm}$. Sphingosine content was determined by the method of Naoi et al. (1974): in brief, free sphingosine base was released from glycolipid samples by acid hydrolysis and ether extraction, reacted with fluorescamine and monitored for fluorescence using a fluorometer. Gangliosides were separated by high-performance thin-layer chromatography (HPTLC) on silica gel plates (Merck, Darmstadt, Germany) in a solvent system of chloroform:methanol:water (CMW) $60: 40: 9$ containing $0.2 \% \mathrm{CaCl}_{2}$. Gangliosides were visualized by resorcinol-HCl spray, and individual bands were quantified by scanning densitometry using a Shimazu CS-910 scanner. Immunostaining of neutral glycolipids separated on Whatman HP-KF silica gel plates was performed as described previously (Fenderson et al., 1987).

\section{Immunohistochemistry}

Frozen sections $(5 \mu \mathrm{m})$ of rabbit uterus were post-fixed with acetone for one minute, air dried and rehydrated with phosphate-buffered saline (PBS) containing $5 \%(\mathrm{w} / \mathrm{v})$ bovine serum albumin (fraction V; Sigma, St Louis, MO, USA). After $30 \mathrm{~min}$, sections were treated with monoclonal antibody $(\mathrm{mAb})$ for $1-2 \mathrm{~h}$ at $4^{\circ} \mathrm{C}$, followed by fluorescein isothiocyanate-conjugated rabbit anti-mouse IgG plus IgM (Dakko, Carpinteria, CA, USA) for $1 \mathrm{~h}$ at $4^{\circ} \mathrm{C}$. Sections were then washed with PBS, mounted with $70 \%$ glycerol in $50 \mathrm{mmol} \mathrm{Tris-} \mathrm{HCl}^{-1}$ (pH 9.6), and examined using a Zeiss fluorescence microscope with epi-illumination. The following $\mathrm{mAbs}$ that recognize glycolipid antigens were used: AH-6 directed to Ley (Abe et al., 1983), 1A4-E10 directed to Gb3 (Fenderson et al., 1987), SSEA-3 directed to Gb4 (Kannagi et al., 1983), FE-A5 directed to $\mathrm{nLc4}$ (Fenderson et al., 1986a), BE2 directed to H type 2 chain (Young 
et al., 1981), SH-I directed to Le ${ }^{\mathrm{x}}$ (Singhal et al., 1990) and VESP 6.2 directed to sulfated galactosyl glycolipids (Petry et al., 1988).

\section{Results}

\section{Sphingosine and lipid-bound sialic acid analysis}

The glycolipid content of rabbit endometrium was determined quantitatively at various reproductive stages. Neutral and acidic glycolipid fractions corresponding to normalized wet weight of tissue were assayed for sphingosine and lipid-bound sialic acid, respectively. The lipid-bound sialic acid content of endometrium of nonpregnant rabbits (representing total gangliosides) declined by $70 \%$ during the first week of pregnancy, day 6 (Fig. 1). There were no significant changes in lipidbound sialic acid content during later pregnancy. By contrast, the sphingosine content of rabbit endometrium (representing total neutral glycolipids) was unchanged during early pregnancy (day 6), but increased 2.5 fold during middle (day 18) and late (day 26) pregnancy. Thus, the ratio of neutral glycolipids to gangliosides in endometrium increased dramatically during pregnancy.

(a)

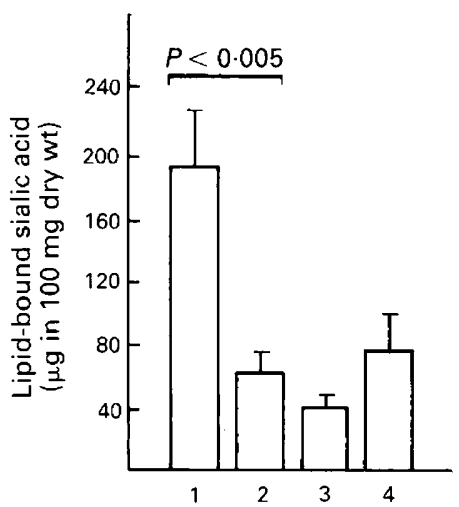

(b)

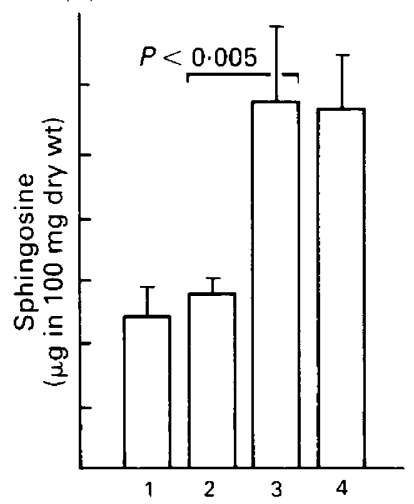

Fig. 1. Quantitative analysis of glycolipid expression in rabbit endometrium during pregnancy: (a) lipid-bound sialic acid content of the acidic glycolipid (ganglioside) fraction; (b) sphingosine content of the neutral glycolipid fraction. Endometrium samples include nonpregnant oestrous stage (1); day 6 early pregnancy (2); day 18 mid-pregnancy (3); and day 26 late pregnancy (4). Data points represent the mean \pm SD of three separate assays. Changes in glycolipid content were evaluated for statistical significance using a two-sample $t$ test.

\section{HPTLC analysis}

The major gangliosides of nonpregnant and pregnant rabbit endometrium were identified using pure ganglioside standards as GM3 and GD3, with minor amounts of GM1, GD1a and GT1b (Fig. 2). Quantitative changes in ganglioside composition during pregnancy were determined by scanning densitometry on replicate HPTLC plates (Table 1). GM3 and GDla content were found to increase dramatically during early pregnancy (day 6), whereas GD3 and GT1b content declined. GD3 was the major ganglioside during mid-pregnancy (day 18), accounting for $45 \%$ of total glycolipid. GDla content declined during mid-pregnancy, but increased during late pregnancy (day 28).

The major neutral glycolipids of rabbit endometrium during early pregnancy (day 6) were similarly identified using pure glycolipid standards, lactosylceramide (CDH), Gb3 and Gb4 (Fig. 3; 


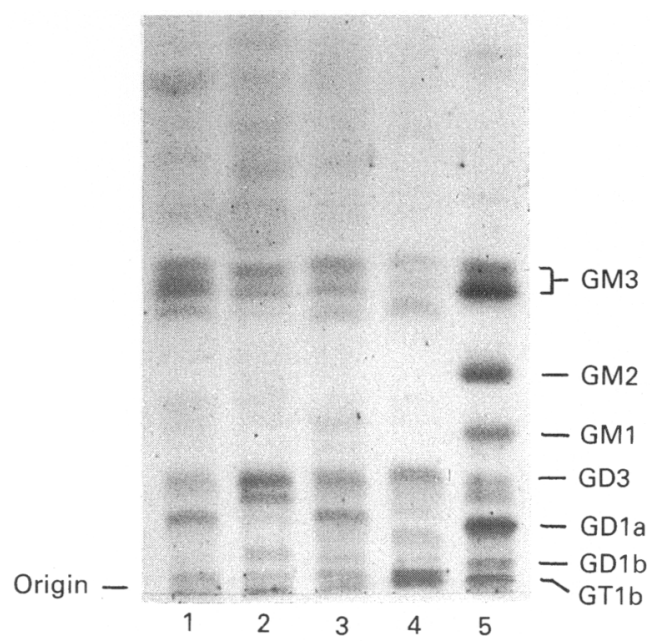

Fig. 2. HPTLC analysis of ganglioside composition in rabbit endometrium during pregnancy. Samples were normalized to contain $1.5 \mu \mathrm{g}$ sialic acid and included day 6 early pregnancy (1), day 18 mid-pregnancy (2), day 26 late pregnancy (3), and oestrus, nonpregnancy (4). A standard set of glycolipids was included (5). After streaking, HPTLC plates were developed by ascending chromatography in a solvent system of chloroform:methanol:water 60:40:9 containing $0 \cdot 2 \% \mathrm{CaCl}_{2}$. Gangliosides were visualized by resorcinol spray. Note that individual gangliosides may resolve as doublets on HPTLC plates owing to discrete differences in fatty acid chain length.

Table 1. Ganglioside composition of rabbit endometrium (percentage of total) at specific stages of pregnancy

\begin{tabular}{lcccc}
\hline Ganglioside & $\begin{array}{c}\text { Oestrous } \\
\text { stage }\end{array}$ & $\begin{array}{c}\text { Day 6 } \\
\text { (early pregnancy) }\end{array}$ & $\begin{array}{c}\text { Day 18 } \\
\text { (mid-pregnancy) }\end{array}$ & $\begin{array}{c}\text { Day 26 } \\
\text { (late pregnancy) }\end{array}$ \\
\hline GM3 & $28 \pm 3^{\mathrm{b}}$ & $52 \pm 10$ & $39 \pm 1$ & $35 \pm 2$ \\
GD3 & $29 \pm 5$ & $15 \pm 3$ & $45 \pm 3$ & $23 \pm 2$ \\
GDla & $5 \pm 2$ & $21 \pm 9$ & $2 \pm 2$ & $20 \pm 1$ \\
GD1b & $9 \pm 3$ & not detected & $7 \pm 1$ & $6 \pm 2$ \\
\hline
\end{tabular}

"Glycolipids are designated in the text according to the recommendations of the IUPAC-IUB Commission on Biochemical Nomenclature (1978), but the suffix OseCer is omitted. Gangliosides (acidic glycolipids containing $\mathrm{N}$-acetylneuraminic acid) are designated according to the nomenclature of Svennerholm (1964).

'Data represent percentages (mean \pm SD) of total resorcinol-positive glycolipid identified by scanning densitometry in three to six separate assays.

orcinol). During later pregnancy (day 26) there was an accumulation of $\mathrm{CDH}$ and the appearance of several new glycolipids of unknown structure. The presence of globo-series glycolipids in rabbit endometrium was confirmed by HPTLC immunostaining using mAbs specific for Gb3 and Gb4 (Fig. 3; $1 A 4 E 10$ and $S S E A-3$ ).

The sensitivity of the HPTLC immunostaining method permitted the detection of additional, lacto-series glycolipids in rabbit endometrium (Fig. 3). For example, difucosyl Le ${ }^{y}$ was clearly detected by mAb AH-6 in samples of endometrium from day 6 and day 26 pregnant rabbits. Extended Le $\mathrm{y}^{\mathrm{y}}$ structures, also detected by mAb AH-6, were present during early pregnancy (day 6), but lost during later pregnancy (day 26). In contrast, nonsialylated poly- $N$-acetyllactosamine chains recognized by $\mathrm{mAb}$ FE-A5, and monofucosylated poly- $N$-acetyllactosamine chains recognized by $\mathrm{mAb} \mathrm{SH}-1$, both appeared in endometrium during late pregnancy (day 26). The 
(a)

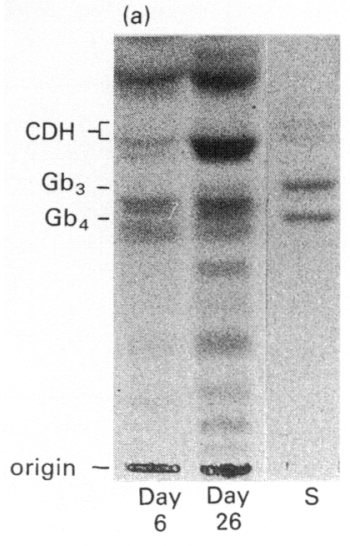

(d)

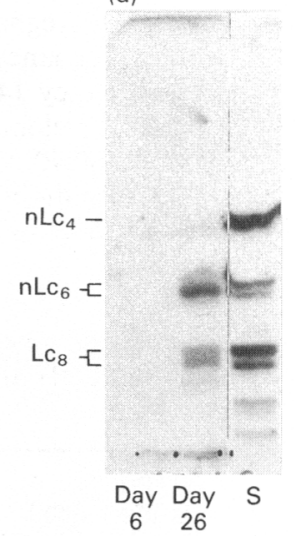

(b)

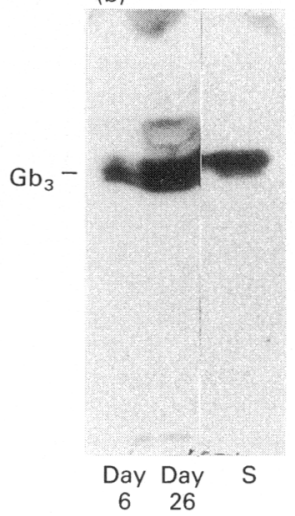

(e)

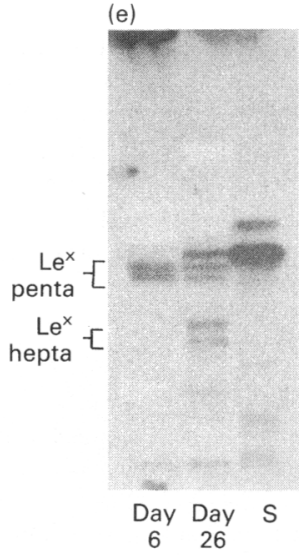

(c)
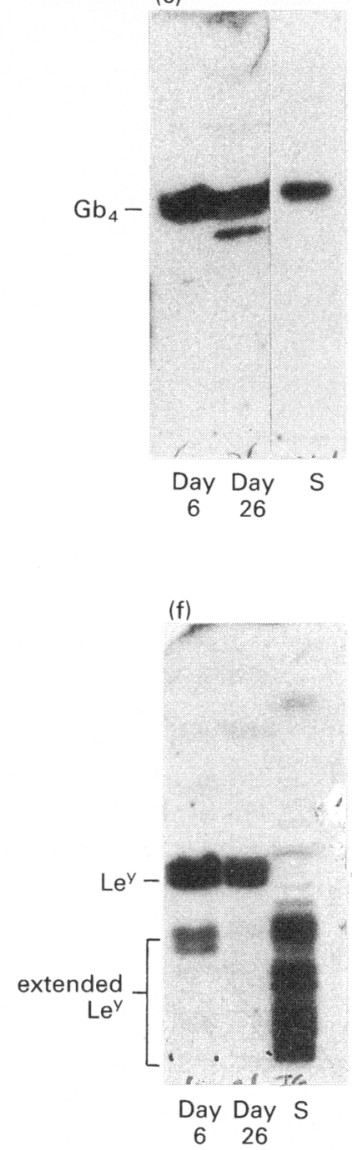

Fig. 3. HPTLC immunostaining analysis of neutral glycolipid composition in rabbit endometrium during pregnancy. Samples were normalized to $2 \mu \mathrm{g}$ sphingosine and included day 6 (implantation stage) and day 26 (late pregnancy). An appropriate standard was included (S). Replicate HPTLC plates were developed in a solvent system of chloroform:methanol:water $50: 40: 10$ containing $0 \cdot 05 \% \mathrm{CaCl}_{2}$, and stained for carbohydrate by (a) orcinol/sulfuric acid spray (orcinol), or labelled with monoclonal antibodies (b) 1A4-E10, (c) SSEA-3, (d) FE-A5, (e) SH-1 or (f) AH-6. Results represent autoradiographs of an ${ }^{125}$ I-labelled protein A detection system.

neutral glycolipids of nonpregnant (oestrus-stage) endometrium were not examined by HPTLC immunostaining.

\section{Immunohistochemical analysis}

The distribution of specific glycolipid antigens within the uterus of nonpregnant and pregnant rabbits was examined by the indirect immunofluorescence method (Figs 4 and 5). Of the several mAbs directed to neutral glycolipid antigens used in this study, mAb AH-6 (anti-Le ${ }^{y}$ ) showed the strongest immunohistochemical reaction with endometrium. MAb AH-6 strongly labelled surface epithelium and glandular epithelium in uteri of both nonpregnant (oestrus stage) and early pregnant (day 6) rabbits (Fig. 4a-d). Epithelial cells appeared to be less-strongly labelled during later pregnancy (day 26); however, the epithelium is sparse and thin at this stage, making interpretation of results difficult. Of several mAbs directed to acidic glycolipids, VESP $6 \cdot 2$ (antisulfated-galactosyl glycolipid) showed the strongest immunohistochemical reaction. MAb VESP 
Table 2. Summary of monoclonal antibody reactivity with epithelium and stroma of rabbit endometrium at different stages of pregnancy

\begin{tabular}{lcccccccc}
\hline & \multicolumn{2}{c}{ VESP 6.2 } & \multicolumn{2}{c}{ AH-6 } & \multicolumn{2}{c}{ SH-1 } & \multicolumn{2}{c}{ BE2 } \\
Stage & Epithelium & Stroma & Epithelium & Stroma & Epithelium & Stroma & Epithelium & Stroma \\
\hline $\begin{array}{l}\text { Nonpregnant } \\
\text { (oestrus) }\end{array}$ & + & ++ & +++ & - & + & - & - & - \\
$\begin{array}{l}\text { Pregnant } \\
\text { Day 6 }\end{array}$ & ++ & + & +++ & - & + & - & - & - \\
Day 8 & - & - & +++ & - & + & - & - & - \\
Day 26 & - & - & + & - & + & - & - & - \\
\hline
\end{tabular}

Scale is negative $(-)$ to strong positive $(+++)$. Epithelium staining refers to both glandular and luminal components.

6.2 labelled endometrial stromal cells in uteri of both nonpregnant and early pregnant (day 6) rabbits (Fig. 5a-d). Stromal cells were not labelled during later pregnancy (days 8 and 26). MAb VESP 6.2 also labelled the glandular and surface epithelium of the endometrium on day 6 (Fig. $5 \mathrm{c}, \mathrm{d}$ ), but not on day 8 (Fig. 5e, f) of pregnancy. Thus, the VESP 6.2 antigen is expressed by endometrial epithelial cells for only a few days, during the time of uterine receptivity to blastocyst attachment. MAb SH-1 (anti-Le ${ }^{x}$ ) weakly labelled the endometrial epithelium at all stages of oestrus and pregnancy, whereas $\mathrm{mAb}$ BE2 (anti-H type 2 chain) did not label the rabbit uterus at any stage. Results of indirect immunofluorescence assays are summarized (Table 2).
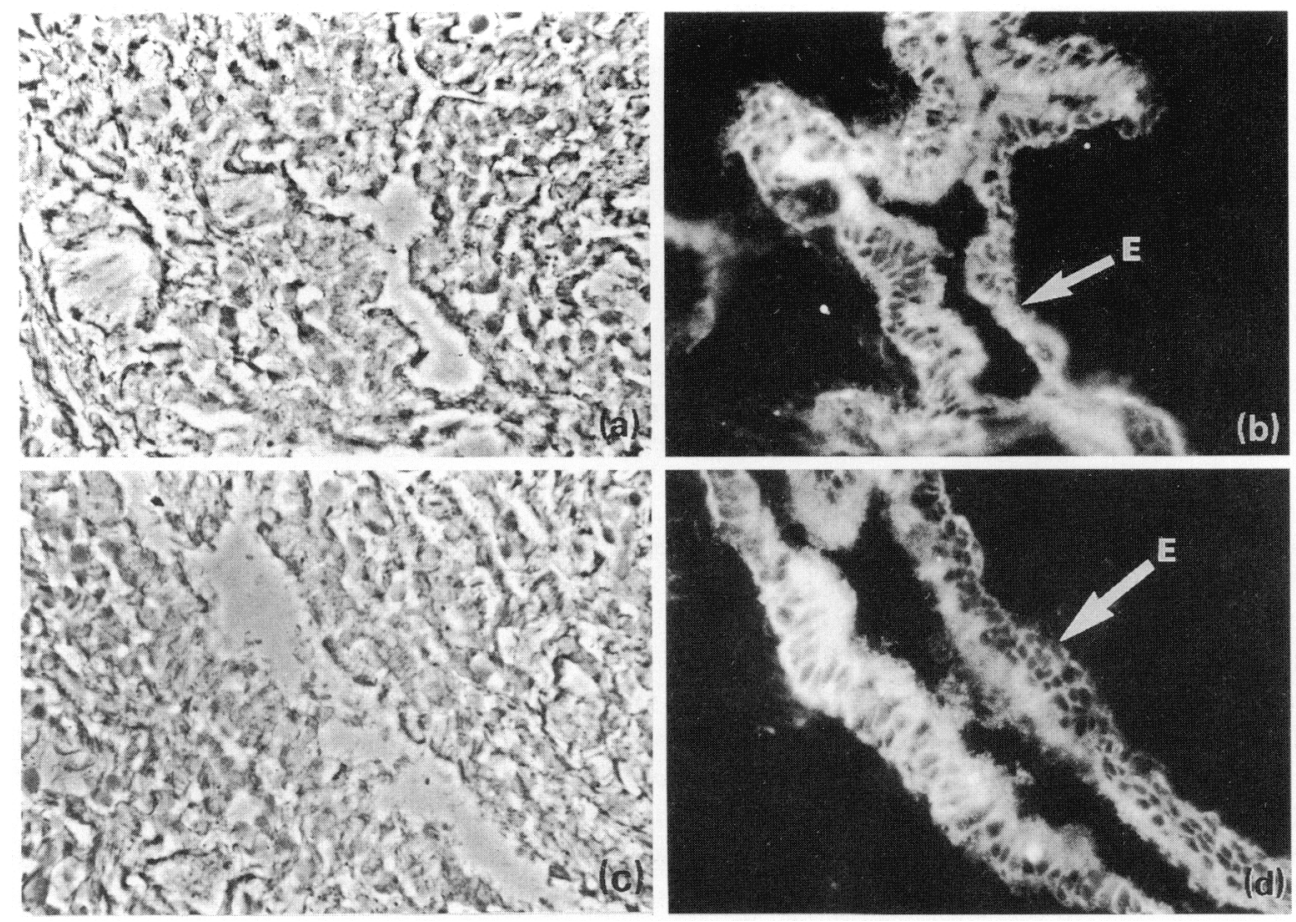

Fig. 4. Indirect immunofluorescence analysis of $\mathrm{Le}^{y}$ antigen expression in rabbit endometrium during pregnancy. Cryostat sections of (a,b) nonpregnant oestrous stage and (c, d) day 6 early pregnant uteri were labelled with monoclonal antibody AH-6 (anti-Le ${ }^{y}$ ). Photomicrographs were taken using phase $(a, c)$ or fluorescence $(b, d)$ microscopy. E: epithelium. 

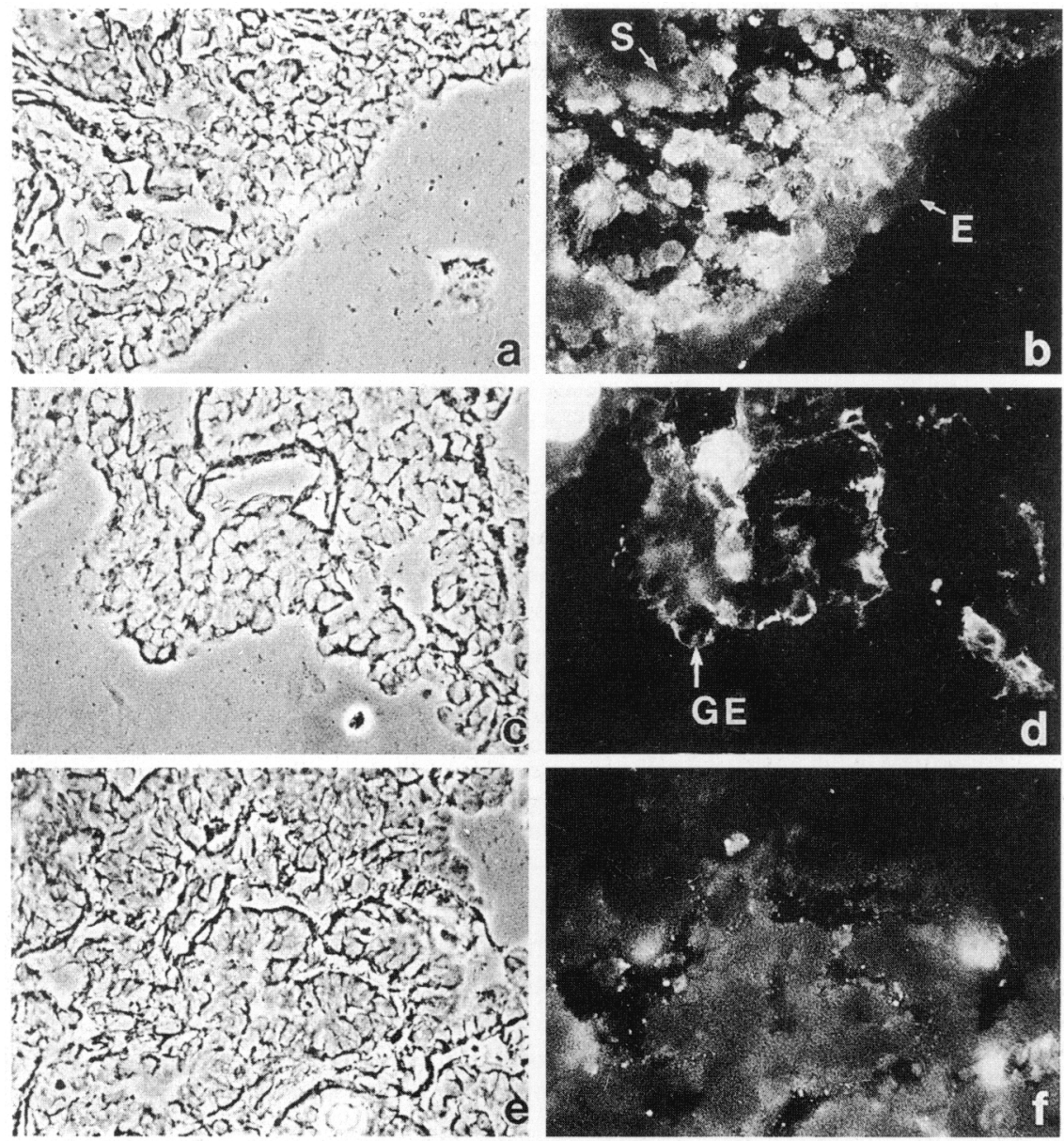

Fig. 5. Indirect immunofluorescence analysis of sulfated galactose antigen expression in rabbit endometrium during pregnancy. Cryostat sections of $(a, b)$ nonpregnant oestrous stage, $(c, d)$ day 6 carly pregnant, and $(e, f)$ day 8 early pregnant uteri were labelled with monoclonal antibody VESP-6.2. Photomicrographs were taken using phase $(a, c, e)$ or fluorescence $(b, d, f)$ microscopy. Abbreviations: E: epithelium; GE: glandular epithelium; S: stroma.

\section{Discussion}

Analysis of glycolipid composition and localization in endometrium provides a first step towards understanding the functional roles of membrane glycolipids in implantation and pregnancy. The results presented here are summarized as follows: (i) the ganglioside content of rabbit endometrium declined rapidly during the first week of pregnancy (by $70 \%$ ), whereas neutral glycolipid content increased approximately threefold during mid- and late pregnancy; (ii) the major gangliosides of rabbit endometrium were identified as GM3 and GD3, and the major neutral glycolipids were identified as globo-series structures $\mathrm{Gb3}$ and Gb4; (iii) additional glycolipid structures, including difucosyl $\mathrm{Le}^{\mathrm{y}}$ and sulfated-galactose, were localized using monoclonal antibodies along the luminal surface of the endometrium during the implantation stage (day 6). The structures of the major glycolipid antigens of rabbit endometrium are summarized in Table 3.

The glycolipids of rabbit endometrium and their changes during pregnancy are remarkably similar to the glycolipid changes that were identified in human endometrium (Zhu et al., 1990). In 
Table 3. Major neutral and acidic glycolipids of rabbit endometrium

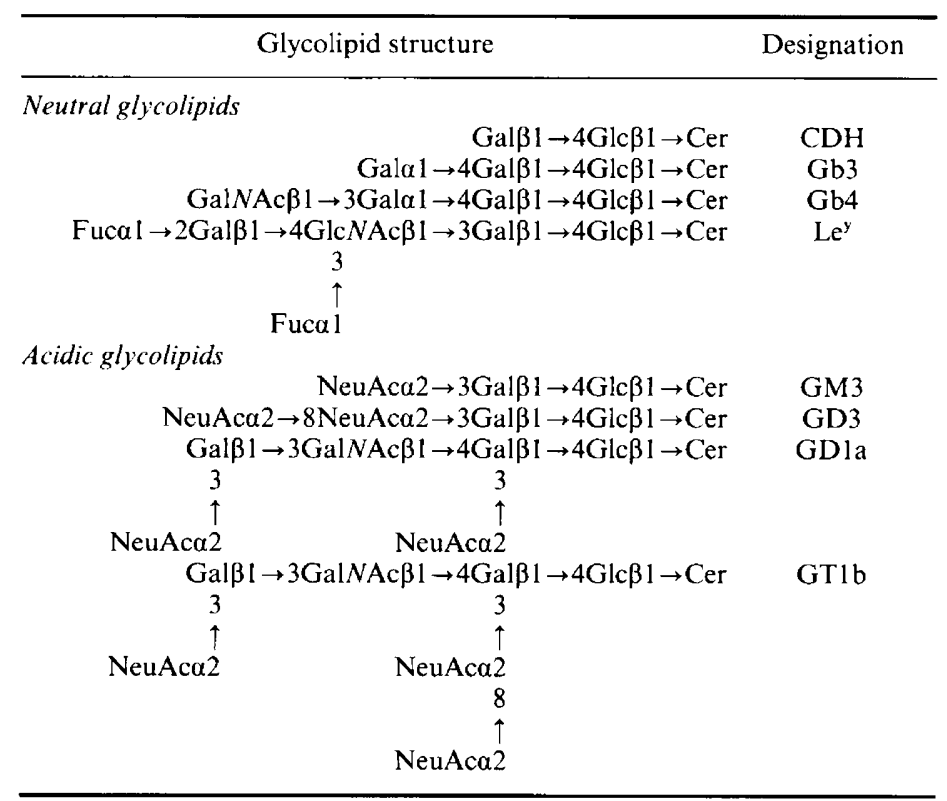

Glycolipid structures were identified by: (i) co-migration on HPTLC plates with pure glycolipid standards; and (ii) HPTLC immunostaining using specific anti-glycolipid monoclonal antibodies.

both species, ganglioside expression declines dramatically during early pregnancy, whereas neutral glycolipid expression increases gradually during the course of pregnancy. As discussed previously (Zhu et al., 1990), these changes in glycolipid expression may facilitate the close apposition of maternal and embryonic cell membranes during implantation by reducing electric charge at the cell surface. A decrease in sialic acid charge has previously been identified in the rabbit uterus at the time of implantation, and postulated to play an important role in regulating trophoblast adhesion (Anderson \& Hoffman, 1984; Anderson et al., 1986). However, regional specificity of blastocyst attachment within the uterus suggests that local changes in charged or other molecules may be more important than the global changes described here.

Stage-specific changes in the glycoprotein composition of the rabbit endometrium have been reported previously. By analysing the surface iodination patterns of isolated uterine epithelial cells, Ricketts et al. (1984) noted quantitative changes in the expression of two proteins (molecular masses 38 and $42 \mathrm{kDa}$ ) between day 4 and day 6.5 of pregnancy. Anderson et al. (1986) noted an apparent loss of sialic acid and a corresponding increase in terminal galactose in the rabbit uterine epithelium during the period of receptivity to implantation. In addition, these workers characterized the appearance of three new glycoproteins (molecular masses 24, 42, and $58 \mathrm{kDa}$ ) during this time. More recently, Bukers et al. (1991) have described regional differences in glycoconjugate expression in the rabbit uterus: differences in lectin staining were observed between the mesometrial and anti-mesometrial surface of the uterine lumen, and between the implantation chamber and the interblastocyst segments.

The specific fucosylated and sulfated antigens that we have identified in rabbit endometrium by indirect immunofluorescence (Figs 4 and 5) have been identified previously in the uteri of other mammalian species. For example, $\mathrm{Le}^{\mathrm{y}}, \mathrm{Le}^{\mathrm{x}}$ and blood group $\mathrm{H}$ antigens are known to be expressed by epithelial cells of mouse endometrium (Babiarz \& Hathaway, 1988; Kimber et al., 1988; Kimber \& Lindenberg, 1990), and the $\mathrm{Le}^{y}$ antigen has been shown to appear on the mouse blastocyst upon exposure to the uterine environment (Fenderson et al., 1986b). In addition, sulfatide 
(sulfated-galactosyl ceramide) has been found to increase dramatically in human endometrial cells during the secretory stage (i.e. the receptive phase) of the menstrual cycle (Kubushiro et al., 1989), and sulfated glycoproteins have been identified as secretory products of the mouse oviduct (EricksonLawrence et al., 1989). In this connection, the carrier molecule for the sulfated-galactosyl epitope recognized by mAb VESP 6.2 in rabbit endometrium could be a glycoprotein, as only trace amounts of sulfated glycolipid were detected in this study by HPTLC analysis (data not shown).

The presence of sulfated galactose epitopes on the surface epithelium of rabbit endometrium during the time for implantation (Fig. 5) focuses attention on sulfated glycolipids or sulfated glycoproteins or both of these molecules as possible recognition signals for trophectoderm endometrium adhesion. Although negatively charged, sulfatide is known to interact strongly with the extracellular matrix protein laminin (Roberts et al., 1988). In addition, poly-sulfate groups of the zona pellucida are considered to mediate fertilization by providing high-affinity receptors for sperm acrosomal proteins (Jones, 1991). The presence of laminin on the blastocyst surface could provide one mechanism for specific recognition during implantation; however, immunochemical studies have not detected laminin on trophectodermal cells at this stage (Carnegie, 1991). The results presented here suggest that the expression of other sulfatide-binding proteins, such as thrombospondin and properidin (see Holt et al., 1989), by trophectodermal cells and their possible role in implantation should be investigated.

In addition to proteins, recognition molecules for carbohydrates may include carbohydrates. For example, we have reported previously that fucosylated $\alpha 1 \rightarrow 3$ lactosamine (i.e. Le $\mathrm{L}^{\mathrm{x}}$ ) structures self-aggregate in the presence of $\mathrm{Ca}^{2+}$ (Eggens et al., 1989), a property which may underlie the role of $\mathrm{Le}^{\mathrm{x}}$ in mediating interactions between embryonic cells during morula compaction (reviewed by Fenderson et al., 1990). These results have been extended by the demonstration of other specific glycolipid-glycolipid interactions, including GM3-asialo-GM2 interaction (Kojima \& Hakomori, 1989) and sulfatide galactosylceramide interaction (Kojima \& Hakomori, unpublished). By analogy, Le $\mathrm{e}^{\mathrm{y}}$, sulfated-galactosyl structures or both on the surface of uterine epithelial cells (Figs 4 and 5) may provide multivalent ligands for cell surface carbohydrates present on the surface of trophectodermal cells of the implanting blastocyst. It should be possible to substantiate this hypothesis using liposome adhesion assays (e.g., Eggens et al., 1989) to identify matching carbohydrate ligands for $\mathrm{Le}^{\mathrm{y}}$ and sulfatide. In addition, it should be possible to test the general role of carbohydrate recognition in implantation using monoclonal anti-carbohydrate antibodies (e.g. AH-6 and VESP 6.2) as blocking agents, in in vitro and in vivo implantation assays.

This study was supported by a Natural Science Foundation of China Grant 3870135 (Z. Zhu), NIH Outstanding Investigator Grant CA42505 (S. Hakomori), and by funds from The Biomembrane Institute (B. Fenderson). We thank J. Stoeck for assistance with manuscript preparation.

\section{References}

Abe, K., McKibbin, J.M. \& Hakomori, S. (1983) The monoclonal antibody directed to difucosylated type 2 chain (Fuc $\alpha \mathrm{l} \rightarrow 2 \mathrm{Gal} \beta \mathrm{l} \rightarrow 4[\mathrm{Fuc} \alpha \mathrm{l} \rightarrow 3] \mathrm{GlcNAc} ; \mathrm{Y}$ determinant). Journal of Biological Chemistry 258, $11793-11797$.

Aminoff, D. (1961) Methods for the quantitative estimation of $\mathrm{N}$-acetylneuraminic acid and their application to hydrolysates of sialomucoids. Biochemical Journal 81, 384-392.

Anderson, T.L. \& Hofiman, L.H. (1984) Alterations in epithelial glycocalyx of rabbit uteri during early pseudopregnancy and pregnancy, and following ovariectomy. American Journal of Anatomy 171, 321-334.

Anderson, T.L., Olson, G.E. \& Hoffman, L.H. (1986)
Stage-specific alterations in the apical membrane glycoproteins of endometrial epithelial cells related to implantation in rabbits. Biology of Reproduction 34, 701-720.

Babiarz, B.S. \& Hathaway, H.J. (1988) Hormonal control of the expression of antibody-defined lactosaminoglycans in the mouse uterus. Biology of Reproduction 39, 699-706.

Bell, S.C., Patel, S.R., Kirwan, P.H. \& Drife, J.O. (1986) Protein synthesis and secretion by the human endometrium during the menstrual cycle and the effect of progesterone in vitro. Journal of Reproduction and Fertility 77, 221-231.

Bukers, A., Friedrich, J., Nalbach, B.P. \& Denker, H. (1991) Changes in lectin binding patterns in rabbit 
endometrium during pseudopregnancy, early pregnancy and implantation. Trophoblast Research 4, 285-305.

Carnegie, J.A. (1991) Immunolocalization of fibronectin and laminin within rat blastocysts cultured under serum-free conditions. Journal of Reproduction and Fertility 91, 423-434.

Chien, J-L., Li, S-C., Laine, R.A. \& Li, Y-T. (1978) Characterization of gangliosides from bovine erthrocyte membranes. Journal of Biological Chemistry 253, $4031-4035$

Dutt, A., Tang, J-P. \& Carson, D.D. (1987) Lactosaminoglycans are involved in uterine epithelial cell adhesion in vitro. Developmental Biology 119, 27-37.

Eggens, I., Fenderson, B.A., Toyokuni, T., Dean, B., Stroud, M.R. \& Hakomori, S. (1989) Specific interaction between $\mathrm{Le}^{\mathrm{x}}$ and $\mathrm{Le}^{\mathrm{x}}$ determinants: a possible basis for cell recognition in preimplantation embryos and in embryonal carcinoma cells. Journal of Biological Chemistry 264, 9476-9484.

Erickson-Lawrence, M.F., Turner, T.T., Ross, P., Thomas, T.S. \& Oliphant, G. (1989) Sulfated oviductal glycoproteins in the rabbit: quantitation by competitive enzyme-linked immunosorbent assay. Biology of Reproduction 40, 1299-1310.

Fenderson, B.A., Nichols, E.J., Clausen, H. \& Hakomori, S. (1986a) A monoclonal antibody defining a binary $\mathrm{N}$-acetyllactosaminyl structure in lacto-isooctaosylceramide $\left(\mathrm{IV}^{6} \mathrm{Gal} \beta \mathrm{I} \rightarrow 4 \mathrm{GlcNAcnLc_{6 }}\right)$ : a useful probe for determining differential glycosylation patterns between normal and transformed human fibroblasts. Molecular Immunology 23, 747-754.

Fenderson, B.A., Holmes, E.H., Fukushi, Y. \& Hakomori, S. (1986b) Coordinate expression of X and $Y$ haptens during murine embryogenesis. Developmental Bio$\log y 114,12-21$.

Fenderson, B.A., Andrews, P.W., Nudelman, E., Clausen, H. \& Hakomori, S. (1987) Glycolipid core structure switching from globo- to lacto- and ganglio-series during retinoic acid-induced differentiation of TERA-2-derived human embryonal carcinoma cells. Developmental Biology 122, $21-34$.

Fenderson, B.A., Eddy, E.M. \& Hakomori, S. (1990) Review article: glycoconjugate expression during embryogenesis and its biological significance. BioEssays 12, 173-179.

Hanai, N., Nores, G.A., Macleod, C., Torres-Mendez, C-R. \& Hakomori, S. (1988) Ganglioside-mediated modulation of cell growth: specific effects of $\mathrm{GM}_{3}$ and lyso- $\mathrm{GM}_{3}$ in tyrosine phosphorylation of the epidermal growth factor receptor. Journal of Biological Chemistry 263, 10915-10921.

Hannun, Y.A. \& Bell, R.M. (1989) Functions of sphingolipids and sphingolipid breakdown products in cellular regulation. Science 243, 500-507.

Hathaway, H.J., Romagnano, L.C. \& Babiarz, B.S. (1989) Analysis of cell surface galactosyltransferase activity during mouse trophectodermal differentiation. Developmental Biology 134, 351-361.

Hewitt, K., Beer, A.E. \& Grinnell, F. (1979) Disappearance of anionic sites from the surface of the rat endometrial epithelium at the time of blastocyst implantation. Biology of Reproduction 21, 691-707.

Holt, G.D., Krivan, H.C., Gasic, G.J. \& Ginsburg, V. (1989) Antistasin, an inhibitor of coagulation and metastasis binds to sulfatide (Gal(3-SO4) $\beta 1 \rightarrow 1 \mathrm{Cer})$ and has a sequence homology with other proteins that bind sulfated glycoconjugates. Journal of Biological Chemistry 264, $12138-12140$.

IUPAC-IUB Commission on biochemical nomenclature (1977) Lipids 12, 455-463.

Jones, R. (1991) Interaction of zona pellucida glycoproteins, sulphated carbohydrates and synthetic polymers with proacrosin, the putative egg-binding protein from mammalian spermatozoa. Development 111, 1155-1163.

Kannagi, R., Cochran, N.R., Ishigami, F., Hakomori, S., Andrews, P.W., Knowles, B.B. \& Solter, D. (1983) Stage-specific embryonic antigens (SSEA-3 and -4) are epitopes of a unique globo-series ganglioside isolated from human teratocarcinoma cells. $E M B O$ Journal 2, 2355-2361.

Kimber, S.J. \& Lindenberg, S. (1990) Hormonal control of a carbohydrate epitope involved in implantation in mice. Journal of Reproduction and Fertility 89, 13-21.

Kimber, S.J., Lindenberg, S. \& Lundblad, A. (1988) Distribution of some Gal $\beta 1-3(4)$ GlcNAc related carbohydrate antigens on the mouse uterine epithelium in relation to the peri-implantational period. Journal of Reproductive Immunology 12, 297-313.

Kojima, N. \& Hakomori, S. (1989) Specific interaction between gangliotriaosylceramide $(\mathrm{Gg} 3)$ and sialosyllactosylceramide (GM3) as a basis for specific cellular recognition between lymphoma and melanoma cells. Journal of Biological Chemistry 264, $20159-20162$.

Kubushiro, K., Kojima, K., Mikami, M., Nozawa, S., lizuka, R., Iwamori, M. \& Nagai, Y. (1989) Menstrual cycle-associated alteration of sulfogalactosylceramide in human uterine endometrium: possible induction of glycolipid sulfation by sex steroid hormones. Archives of Biochemistry and Biophysics 268, 129-136.

Ledeen, R.W. \& Yu, R.K. (1982) Gangliosides: structure, isolation and analysis. Methods in Enzymology 83, 139-191

Lindenberg, S., Sundberg, K., Kimber, S.J. \& Lundblad, A. (1988) The milk oligosaccharide, lacto- $N$-fucopentose I, inhibits attachment of mouse blastocysts on endometrial monolayers. Journal of Reproduction and Fertility 83, 149-158.

Murphy, C.R. \& Rogers, A.W. (1981) Effects of ovarian hormones on cell membranes in the rat uterus. III. The surface carbohydrates at the apex of the luminal epithelium. Cell Biophysics 3, 305-320.

Naoi, M., Lee, Y.C. \& Roseman, S. (1974) Rapid and sensitive determination of sphingosine bases and sphingolipids with fluorescamine. Analytical Biochemistry 58, 571-577.

Nojiri, H., Stroud, M.R. \& Hakomori, S. (1991) A specific type of ganglioside as a modulator of insulindependent cell growth and insulin receptor tyrosine kinase activity: possible association of gangliosideinduced inhibition of insulin receptor junction and monocytic differentiation induction in HL60 cells. Journal of Biological Chemistry 266, 4531-4537.

Pascher, I. (1976) Molecular arrangements in sphingolipids: conformation and hydrogen bonding of ceramide and their implication on membrane stability and permeability. Biochimica et Biophysica Acta 455, 433-451. 
Petry, K., Nudelman, E., Eisen, H. \& Hakomori, S. (1988) Sulfated lipids represent common antigens on the surface of Trypanosoma cruzi and mammalian tissues. Molecular Biochemistry and Parasitology 30, 113-122.

Ricketts, A.P., Scott, D.W. \& Bullock, D.W. (1984) Radioiodinated surface proteins of separated cell types from rabbit endometrium in relation to the time of implantation. Cell and Tissue Research 236, 421-429.

Roberts, D.D., Wewer, M.R., Liotta, L.A. \& Ginsburg, V. (1988) Laminin-dependent and laminin-independent adhesion of human melanoma cells to sulfatides. Cancer Research 48, 3367-3373.

Singhal, A.K., Orntoft, T.F., Nudelman, E., Nance, S., Schibig, L., Stroud, M.R., Clausen, H. \& Hakomori, S. (1990) Profiles of Lewis and glycolipids in sera of patients with adenocarcinoma. Cancer Research 50, 1375-1380.

Springer, T.A. \& Lasky, L.A. (1991) Sticky sugars for selectins. Nature 349, 196-197.
Svennerholm, L. (1964) The gangliosides. Journal of Lipid Research 5, 145-162.

Thompson, T.E. \& Tillack, T.W. (1985) Organization of glycolipids in bilayers and plasma membranes of mammalian cells. Annual Reviews of Biophysics and Chemistry 14, 361-386.

Vance, D.E. \& Sweeley, C.C. (1967) Quantitative determination of the neutral glycosylceramides in human blood. Journal of Lipid Research 8, 621-630.

Young, W.W., Portoukalian, J. \& Hakomori, S. (1981) Two monoclonal anticarbohydrate antibodies directed to glycosphingolipids with a lacto- $N$-glycosyl type 2 chain. Journal of Biological Chemistry 256, 10967-10972.

Zhu, Z., Deng, H., Fenderson, B.A., Nudelman, E.D. \& Tsui, Z. (1990) Glycosphingolipids of human myometrium and endometrium and their changes during the menstrual cycle, pregnancy and ageing. Journal of Reproduction and Fertility 88, $71-79$.

Received 26 June 1991 